\title{
The PWM Control of the Three-phase Induction Motor
}

\author{
Ping Wei, jinpeng Yu, Fatao Shi, Xiao Wei, Yan Wang, Quanwen Zhao \\ (College of Automation Engineering, Qingdao University, Qingdao 266071, China) \\ 1078114468@qq.com
}

\begin{abstract}
Keywords: The three-phase induction motor; MATLAB; The PWM control technology
Abstract. In this paper, a pulse width modulation (PWM) control approach to speed trackong control is developed for the three-phase induction motor in electric vehicles. The PWM technique is amployed to design controllers. By incorporating the three-phase bridge recifier into the motor based on the PWM technique, the PWM control approach is developed.The proposed control method is able to overcome the disadvatage of the motor in the traditional design procedure.In addition, it is proved that the tracking error converges to a small neighborhood of the all origin and all the closed-loop signals are bounded. The results of the MATLAB simulation illustrate the effectiveness of the proposed approach.
\end{abstract}

\section{Introduction}

In recent years, induction motors (IMS) have been widely utilized for modern electrical drives due to their simple construction、 low cost and high reliability. However, the control of IM is hard because of the complexity of the system. Therefore, many control techniques have been proposed to control the motor system, such as the technique of the PWM speed control, has gained rapid development with the development of power electronics [1] and microelectronics technology [2], the microprocessors control and the digital control technology. They have been successful in inverter applications [3, 6], which makes it become more and more popular. In addition, the PWM control, in particular, is considered to be one of the popular techniques for controlling the complexity of the system of the three-phase induction motor. It is by adjusting the pulse width and the pulse duty ratio to regulate the average voltage. The PWM technology [7], accompanied by the development of power electronic devices, has a good development and currently has matured. By using the PWM technique, the inverter output waveform can be improved to reduce harmonics and torque ripple. it simplifies the structure of the inverter, to speed up the adjustment rate and improve the dynamic response of the system. In the field of electric drive, it has great significance to solve variable speed motor [8]. In this paper, it has been proved that it be an effective approach to control there-phase induction motor, the simulation results has proved the effectiveness of the proposed approach.

\section{Control mode}

The PWM control mode from the polar of the pulse modulation, can be divided into unipolar and bipolar points: it is called unipolar modulation that the polarity of the carried signal and the reference signal polarity is not changing; on the contrary, it is called bipolar modulation that the triangular carried signal and a sine wave signal are with positive and negative polarity.

The reference wave frequency determines the output frequency, the number of pulses per half cycle of $P$ depends on the carrier frequency. Namely:

$$
p=\frac{f_{c}}{2 f_{a}}
$$

Ur stands for the amplitude of the reference voltage signal; Uc stands for the ratio of the amplitude of the triangular carrier signal; $\mathrm{m}=\mathrm{Ur} / \mathrm{Uc}$ stands for the modulation factor. When the modulation changes from 0 to 1.The pulse width changes from 0 to $\pi / p$, the output voltage changes from 0 to $\mathrm{E}$. The modulation principle of Sinusoidal pulse width: bipolar output voltage waveform is in the range of 
$0 \sim 2 \pi$ that is symmetric about the center, and in the range of $0 \sim \pi$ that is about the axis of symmetry, its Fourier series expansion for

$$
\begin{aligned}
& U_{0}(t)=\sum_{n=1,3,5 \ldots}^{\infty} B_{n} \sin \omega t \\
& B_{n}=\frac{2}{\pi} \int_{0}^{\pi} u_{0}(t) \sin \omega t d(\omega t)
\end{aligned}
$$

Formula (4-6): the output voltage can be seen as the amplitude of E, the frequency and the amplitude of the square wave of $2 \mathrm{E}$, the sequence of the negative pulse frequency (the start and end points are superimposed

$$
B_{n}=\frac{4 E}{\pi}\left[1-\sum_{j=1}^{p}\left(\cos n \alpha_{2 j-1}-\cos n \alpha_{2 j}\right)\right]
$$

The output voltage is

$$
U_{0}(t)=\sum_{n=1,3,5 . .}^{\infty} \frac{4 E}{n \pi}\left[1-\sum_{j=1}^{p}\left(\cos n \boldsymbol{\alpha}_{2 j-1}-\cos n \alpha_{2 j}\right)\right] \sin \omega t
$$

Fundamental component of the output voltage

$$
U_{01}(t)=\frac{4 E}{n \pi}\left[1-\sum_{j=1}^{p}\left(\cos n \alpha_{2 j-1}-\cos n \alpha_{2 j}\right)\right] \sin \omega t
$$

It should be noted that the point of view of the main circuit for the bipolar modulation is always alternating on-off because of the same bridge arm of the two switching elements; it is also easy to cause short circuit, causing circulation. To prevent the circulation, it is necessary to trigger an additional delay links and set the dead zone.

\section{MATLAB simulation design}

The control circuit works as the follows: according to the natural sampling, the three high-frequency sine wave and triangular carrier are compared by the results of each channel and then it is to generate the opposite of the original signal control waves by the inverter, respectively, the upper and lower control arm of the IGBT will be turned on and off. The Six Road PWM waves generated are used to be controlled six IGBT to turn off, which generates the three-phase alternating current at the load with the same frequency of the modulation wave.

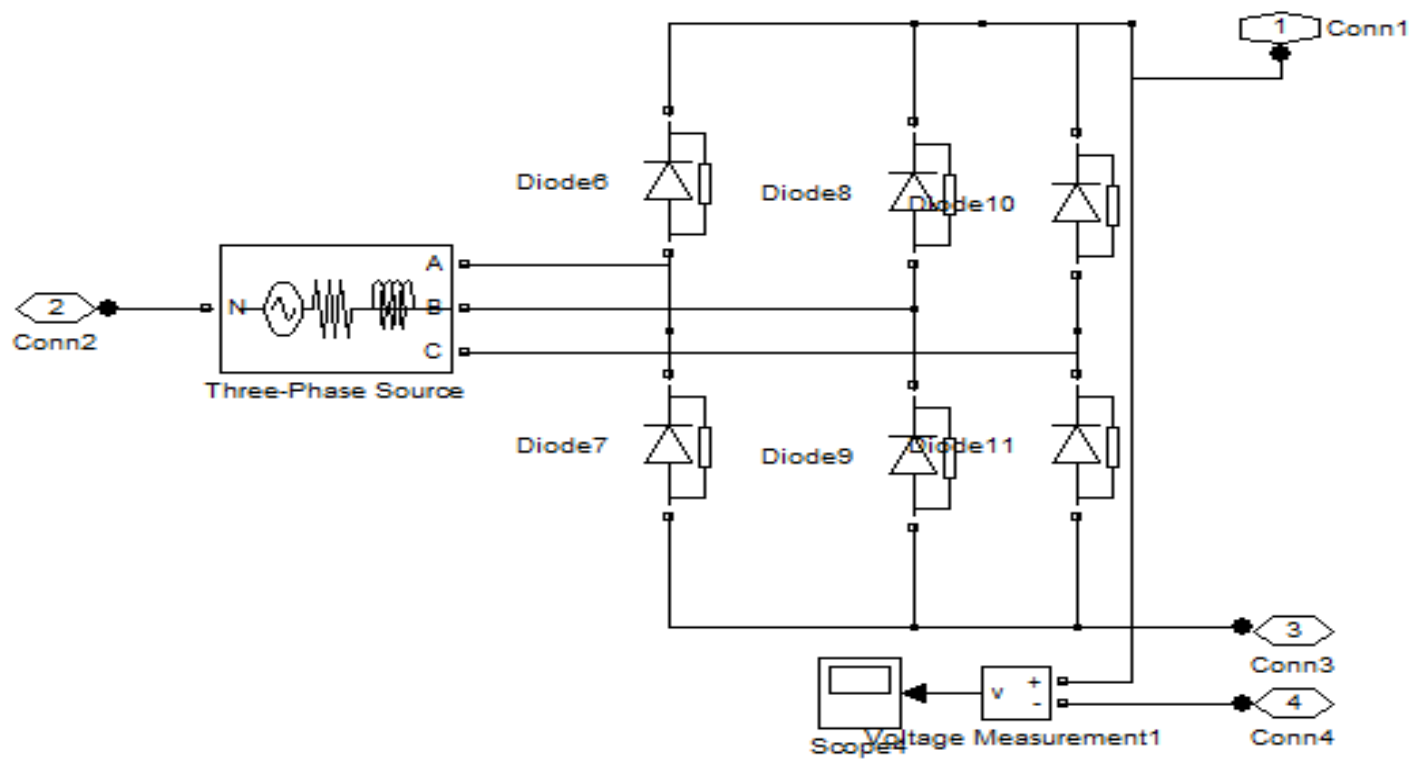

Fig1.The three-phase bridge rectifier module

As is shown in the Fig1: choose the three-phase voltage source module from the three-phase source in SimoPwerSystems of Electrical Sources library. Set the amplitude of 380V. Select 6 diode modules in Power Electronics library. Each module is connected by a three-phase bridge rectifier circuit. And analyze the simulation waveform with a voltmeter module and a Scope block. 


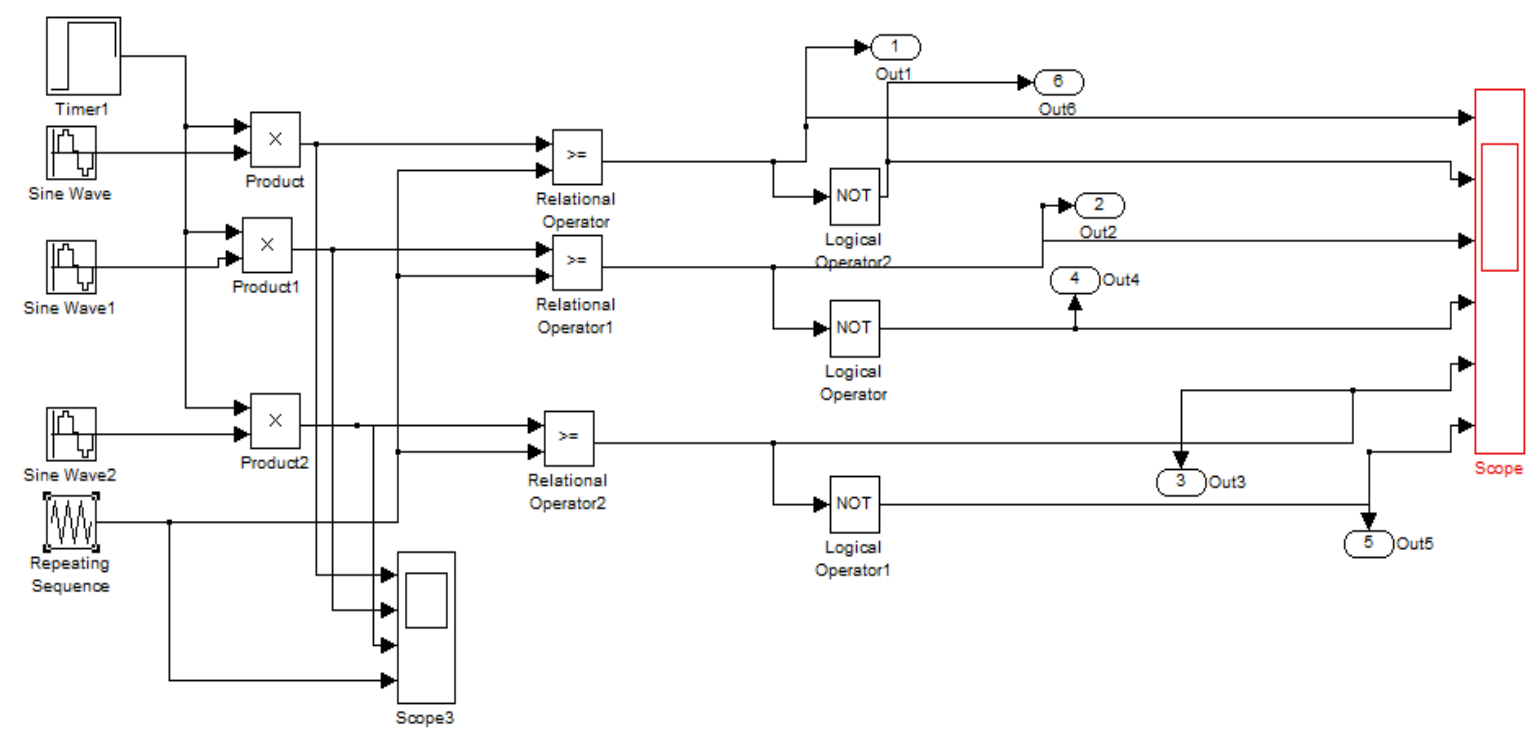

Fig2. The PWM inverter circuit control module

As is shown in the Fig2:Select a Timer module from the Extra Library Sim PowerSystems library, and sinusoidal modulation signal is multiplied. Change the amplitude of the sinusoidal modulation signal by setting the Timer different times in different parameters. Specific analysis is described in detail in the next section- Simulation results.

\section{Simulation results and analysis}

Set the motor operating parameters: the rated power of $2.2 \mathrm{kw}$, the rated line voltage of $380 \mathrm{v}$, the frequency of $50 \mathrm{~Hz}$, the rated speed of $1423 \mathrm{rpm}$, the stator resistance of $3.478 \mathrm{Ohm}$, the stator leakage inductance of $12.54 \mathrm{mH}$, the rotor resistance of $2.546 \mathrm{Ohm}$, the rotor leakage inductance of $12.26 \mathrm{mH}$, the magnetizing inductance of $332.9 \mathrm{mH}$, the moment of inertia of $0.0131 \mathrm{~kg} . \mathrm{m} . \mathrm{m}$, the pole pairs of 2 .

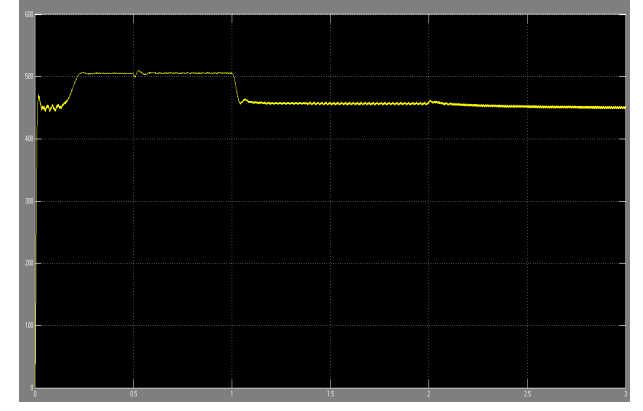

Fig 3. The three-phase rectifier voltage waveform

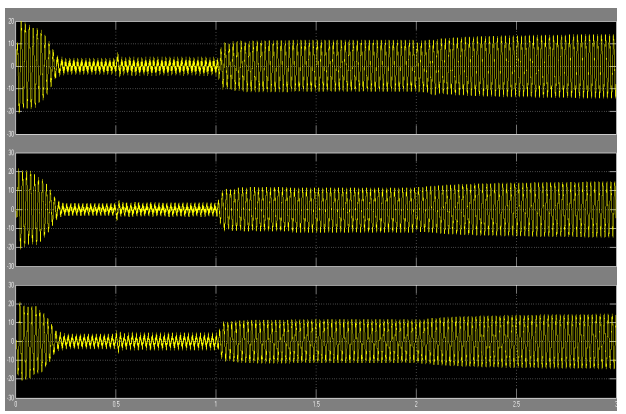

Fig 5. The stator phase current waveforms

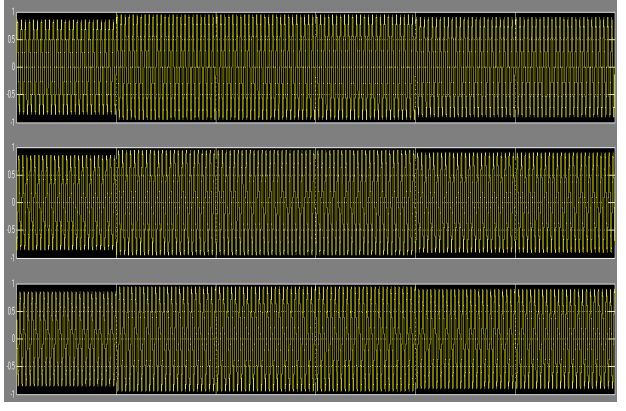

Fig4. The sinusoidal modulation signal

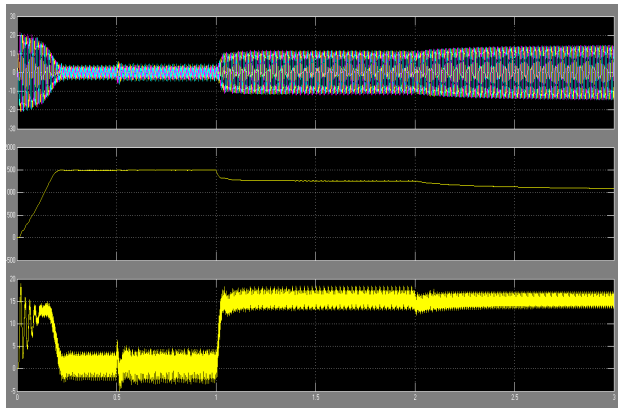

Fig 6. The stator phase current and the torque waveforms As is shown in Fig1:when the first motor with on-load is operation for 1s, the voltage is near 500V; the motor with the rated load after $1 \mathrm{~s}$, the voltage is near $460 \mathrm{~V}$; so the capacitor has stable voltage. As is shown in Fig2:the sinusoidal modulation signal can control the six IGBT to turn off or on. As is shown 
in Fig3-4: when the three-phase induction motor starts at the rated voltage s, the maximum starting current is 3-4 times; when the motor with on- load, the motor speed is basically stable at near $1500 \mathrm{rpm}$, the torque is essentially zero, the no-load current is very small. When the time is $0.5 \mathrm{~s}$, the motor with the rated load, the electromagnetic torque is the rapid growth and the load torque are equal with the electromagnetic torque .

\section{Summary}

Based on the PWM technique, the proposed control procedure is developed to control the three-phase induction motors in electric vehicles. The proposed control makes sure that the motor speed can track the expected speed of the motor and the tracking error converges to a small neighborhood of the origin. In MATLAB simulation, the simulation results show that the proposed control method can overcome the disadvantage of the complexity of the motor and sure that the system can track the desired signal. This study has lots of practical application value.

\section{References}

[1] B.K. Bose. Modern power electronic and AC drives [M]. Upper Saddle River, NJ, USA: Prentice Hall PTK . 2002: 178-186.

[2] S.Bernent.Recent developments of high- power converters for industry and traction application [J]. IEEE trans on power electronics. 2000, 15(6): 1102-1117.

[3] Yongdong L, Yue G, Xuan H. Development of PWM control technology in multi-level converter IJ]. Power Electronics. 2005, 39(5): 2-6.

[4] A. Nabea, I. Takahashi, H. I. Akag. A new neutral—point clamped PWM inverter[J]. IEEE Trans Ind Applicat.1981, 17(5): 518—523.

[5] N. Celanovic, D. Boroyevich.A comprehensive study of neutral- point voltage balancing problem in three- level neutral- point- clamped voltage source PWM inverters[J].IEEE Transactions on Power Electronics. 2000, 15: 242-248.

[6] Weidong J, Qunjing W, Xiaofeng S. Low frequency oscillation of neutral point voltage of neutralpoint clamped three-level VSI under SVPWM control IJ].Proceedings of the CSEE. 2009, 29(3): 49-55.

[7] R. M Tallam, R. Naik, T. A. Nondah. A carrier based PWM scheme for neutral—point voltage balancing in three-level inverters [J].IEEE Transactions on Industry Applications. 2005, 41(6): $1734-1743$.

[8] Cungang H, Qunjing W, Guoli L. A neutral-point potential balancing algorithm three level inverter based on virtual-space. Vector IJ]. Trans-actions of China Electro technical Society . 2009, 24(5): 100-107. 